Article

\title{
Four Paradoxes of the User-Provider Interface: A Responsible Innovation Framework for Sea Ice Services
}

\author{
Berill Blair $^{1, *}$, Olivia A. Lee ${ }^{2}$ and Machiel Lamers ${ }^{1}$ \\ 1 Environmental Policy Group, Wageningen University and Research, 6706 KN Wageningen, The Netherlands; \\ machiel.lamers@wur.nl \\ 2 International Arctic Research Center, University of Alaska Fairbanks, Fairbanks, AK 99775, USA; \\ oalee@alaska.edu \\ * Correspondence: berill.blair@wur.nl
}

Received: 29 November 2019; Accepted: 1 January 2020; Published: 7 January 2020

check for updates

\begin{abstract}
In the Arctic region, sea ice retreat as a decadal-scale crisis is creating a challenging environment for navigating long-term sustainability. Innovations in sea ice services can help marine users to anticipate sea ice concentration, thickness and motion, plan ahead, as well as increase the safety and sustainability of marine operations. Increasingly however, policy makers and information service providers confront paradoxical decision-making contexts in which contradictory solutions are needed to manage uncertainties across different spatial and temporal scales. This article proposes a forward-looking sea ice services framework that acknowledges four paradoxes pressuring sea ice service provision: the paradoxes of performing, contradictory functions embedded in sea ice services, contradicting desired futures and the paradox of responsible innovation. We draw on the results from a multi-year co-production process of (sub)seasonal sea ice services structured around scoping interviews, workshops and a participatory scenario process with representatives of marine sectors, fishers, hunters, metservice providers, and policy experts. Our proposed framework identifies institutionalized coproduction processes, enhanced decision support, paradoxical thinking and dimensions of responsible innovation as tactics necessary to address existing tensions in sea ice services. We highlight the role of socio-economic scenarios in implementing these tactics in support of responsible innovation in sea ice social-ecological systems. The article concludes with a discussion of questions around equity and responsibility raised by the ultimate confirmation that enhanced information, data infrastructures, and service provisions will not benefit all actors equally.
\end{abstract}

Keywords: climate change; sea ice services; social-ecological systems; responsible innovation; sustainability

\section{Introduction}

\subsection{Background}

In the Arctic, rapid and extensive impacts from climate change have already had significant implications for social, ecological and geophysical systems, with further changes projected even by emissions-conservative scenarios [1]. According to some projections, the summer Arctic may be nearly sea ice free by the 2030s [2]. The communities and sectors that depend on either the presence or the predictable absence of sea ice are seeking decision support for an ever-uncertain operating environment [3]. This puts the experts who provide information services, such as the meteorological institutes that provide ice charts and forecast products for marine mobile sectors, on the front lines of managing rapid change by the design and innovation of user-centric services. Currently, 
the development of Arctic observing networks, as well as information and service infrastructures are on the rise. These developments can be seen in the field of metocean (meteorological and oceanographic) forecast provision as well as in sea ice services. Sea ice services provide sea ice information such as type, thickness, concentration, drift, and forecast of expected conditions. This is different from sea ice system services, which refer to the suite of benefits humans derive from sea ice [4], a distinction we return to later. In sea ice services, the same trend can be observed as in Arctic science in general: a growing intention to produce and disseminate salient, user-focused information to reduce risks in cross-scale and cross-sectoral decision making, while increasing the capacity to adapt to change. This demands interdisciplinary and multi-stakeholder collaboration.

While there is increasing interest in direct engagement with interdisciplinary partnerships to better support the forecast needs of maritime stakeholders, barriers exist that impact the usability of products, stemming from differences in what is needed and what is available, and between scientific-minded service providers and their practices-based user groups [5-8]. In order to better tend to user needs, the co-production of services has become the go-to platform for improvements through long-term, interdisciplinary, and intersectoral engagements [9]. In the recent evolution of metocean and sea ice services co-production, it is often seen as a normative challenge to address the usability gap through pragmatic, interactive and iterative approaches, but one that is at times short-sighted with respect to indirect social forces influencing and being influenced by available services [10]. Beyond considering collaborative work, actors have to also consider wider policy frameworks, institutions, societal needs, political discourse, cultural frameworks, or markets for climate information [11], and evaluate the success of co-production accordingly [10]. The challenge remains in anticipating whether and how the changing informational landscape will privilege certain sectors and stakeholder groups over time, and to determine what kind of results will impact the safety and sustainability of maritime actors and their activities. Sustainability therefore demands a dynamic and continuous evaluation of impacts and adaptive capacities due to the effects of innovation. As informational services grow and improve, and knowledge is disseminated at ever-faster speeds, the ripple effects of innovation among diverse and competing stakeholders is also evolving. A custom information governance approach that addresses procedures of coordination and collaboration, and the balancing of powers and interests against principles of responsible innovation would be useful in facilitating maximum responsiveness to stakeholder perspectives [12].

\subsection{The Pervasiveness of Paradox}

We are living in an unprecedented evolutionary phase of life on Earth, in which anthropogenic forces are altering planetary ones, bringing urgency to the coordination and management of changes yet to come [13]. In the Arctic, the tensions that are emerging from the process of mitigating risks, turning risks into opportunities and speculating the limits of adaptation for diverse groups of stakeholders both from within and outside the region, increasingly pose irresolvable dilemmas without neat policy solutions [14]. For example, diminishing sea ice enables shorter shipping routes, longer shipping seasons, increased resource development and economic revenue for communities; but it also results in unstable or absent platforms for hunting and fishing for Indigenous communities, decreased albedo effect, increased ocean warming, decreased biodiversity, increased coastal erosion, and increasing emissions of black carbon, greenhouse gasses, and pollution from increased traffic [15]. As a result, groups of stakeholders compete and advocate for different mobility patterns, or favor certain development scenarios over others. These are tensions of a paradox state, which no policy choice can resolve because contradictory or opposing solutions are needed, and solutions are interwoven $[14,16]$. There is a persistence in the push-and-pull between synergies and tradeoffs in paradox, in which tradeoffs (e.g., cryospheric changes facilitating or hampering certain activities) can become synergies enabling actors to claim winning from loss $[14,17]$ (e.g., the catastrophe of Greenland's melting ice sheet revealing economic opportunities via the export of excess sand). 
Making decisions and planning sustainable futures in paradoxical conditions is especially challenging and demands a 'working through', as opposed to a 'resolution' focused lens [16]. Working through entails a process reoriented toward accentuating polarities in perspectives, critiquing patterns of thought, exploring alternate explanations, expanding the scope of political thinking and challenging simplistic solutions. As Arctic communities, sectors, and institutions grapple to learn and adapt to a continually changing circumpolar north, science and research play crucial roles in helping stakeholders and policy makers consider options and manage dilemmas. This is true for the ever-growing contribution of climate and environmental forecast products in the decision making of Arctic actors.

In turn, the experts who provide decision support tools such as sea ice services face paradoxical conditions under what change management literature has termed the paradoxes of performing [16]. These conditions stem from the duality of multiple requirements. Increasingly, experts have to be at once stakeholder-oriented by coproducing, collaborating, and production-oriented by advancing high-impact research. Likewise, experts must be responsive to evolving user needs, while maintaining high quality and reliability of products. Throughout this process, experts are expected to take control by leading development with confidence, while simultaneously empowering users and revealing own limitations, uncertainties and asking for input. This complex web of demands is compounded by the often diverging needs and priorities of stakeholder groups, private versus public interests, and heightening awareness of the role of informational governance in global sustainability $[18,19]$. Scientific problem solving normally thrives under conditions of consistency and clear problem definition, but paradoxes prevent such clarity. This is increasingly true for scientific and technological innovation in support of maritime operations, yet the long-term safety and sustainability of these activities and the Arctic communities they support, depend on it. The transitions unfolding at the pan-Arctic as well as global scales impact what information stakeholders need just as in return, what is or isn't provided shapes socio-economic realities [20].

\subsection{Participatory Scenario Processes}

Scenarios are a form of anticipatory process. Scenarios can be used to deliberate about possible future events and risks in the present, to imagine upcoming emergent changes and to identify influential drivers of change. Such anticipatory processes enable us to explore important dynamics between present and future system states, to imagine the trajectory of changes yet to come and to use the future to work through complexity [21-23]. Participatory scenario processes are built on collective intelligence in knowledge creation, using the diverse expertise and generational wisdoms of participants and their narratives to imagine common futures [24,25]. The shared imagining of multiple possible futures and even the imagining of the unknowable (what is truly uncertain) allows communities to think ahead and consider what strategies will lead to best or most resilient futures. This does not mean that scenarios forecast futures with certainty, or that we should strive to colonize futures based on today's knowledge [21]. Rather, scenarios and anticipatory methods are useful as tools to complement a suite of understandings and capacities about how the present drives the future. Strategies, in turn, may range from interventions to prevent undesired changes, to inaction when the scope of uncertainties are beyond our current understandings and any treatment plan may create more harm than good [21].

\subsection{Research Aim, Objectives and Questions}

In this article we seek to obtain a system-level understanding of the nexus between sustainable Arctic futures, responsible innovation, and the provider-user interface of sea ice services. By doing so, we hope to contribute to knowledge coproduction solutions for increased equity in sustainability, with priorities set by the breadth and depth of societal applications that these solutions can inform. We present results from a two-year stakeholder engagement process of the SALIENSEAS project (Enhancing the Saliency of Climate Services for Marine Mobility Sectors in European Arctic Seas) with a diverse group of stakeholders with expertise in sea ice services as well as operational and policy issues relevant for Arctic mobile sectors. We first frame the dynamics of sea ice services provision 
from a sea ice social-ecological systems perspective, observing the variety of often contradictory benefits accrued to stakeholders from sea ice that create relevant research needs, stakeholder-desired outcomes, and at times seemingly irresolvable tensions for service providers. We then explore the complementary role of socio-economic scenarios in overcoming these tensions or paradoxes to support responsible innovation [26]. Finally, we situate the scenario output in a multi-stakeholder, multi-criteria coproduction hierarchy [27] of sea ice information services with a forward-looking implementation schematic reoriented to support responsible innovation in the 'Arctic paradox' [14,28]. We answer the following questions:

1. What are the institutional considerations of responsible innovation governance in sea ice services, taking into account the challenges posed by diverse scales of interests?

2. Given that both short and long temporal scales drive stakeholders' adaptive actions and the need for innovation, what spaces for intervention are revealed from the ordering of sea ice services within a multidimensional social-ecological system hierarchy?

Building on the social-ecological systems [29] and responsible innovation [26] literature, subsequently we turn to a conceptual overview of sea ice social-ecological systems and equity. This is followed by a description of our approach to data collection and analysis, and the presentation of our results with an in-depth discussion of the implications of key findings.

\section{Conceptual Framework}

\subsection{Sea Ice Social-Ecological Systems}

We use a working definition of sustainability adopted from Leach et al. (2018) as a dynamic one referring to the "long-term maintenance of desirable and meaningful life support systems which are biophysically, culturally and socially determined" [30]. In doing so, we too consider sustainability as both a process and outcome of coupled environmental and social dimensions and their local and cross-scale interactions. We conceptualize sustainability, therefore, not as an equilibrium state, but rather a variable and dynamic operating space within the boundaries of adaptive thresholds.

Coupled human-environment systems, also called social-ecological systems (SES) are linked social and environmental systems [29,31]. SES bring to prominence the recognition that the sustainability of humans and their patterns of actions and institutions, as well the sustainability of the living and non-living components of the environment, are intertwined. As such, the effectiveness of governing institutions in SES is a function of fit with both the biophysical and social domains in which they operate [32-34]. Sea ice SES encompass multi-jurisdictional geophysical-social-ecological features, presenting special governance challenges and opportunities for sustainability. These issues are well-explored through the concept of sea ice system services (SISS) [4,35]. SISS provides a wide-ranging typology of benefits humans gain from sea ice, highlighting sea ice as an inherently interdependent set of common pool resources across the Arctic [36]: Sea ice offers regulating services (e.g., Arctic and global climate), provisioning services (e.g., sea ice as a stable platform for activities), cultural services (e.g., subsistence activities) and supporting services (e.g., sea ice as a habitat and driver of biodiversity). Sea ice clearly emerges as a common pool resource through SISS, providing the impetus for international coordination and management of socially and economically relevant sea ice services. For the remainder of this paper, we continue using the term sea ice services to refer to sea ice-relevant informational services and forecast provision, and the acronym SISS to refer to the benefits sea ice provides to the linked SES.

Sea ice SES reveal often incompatible stakeholder values embedded within some SISS resulting in contradictory functions. Sea ice retreat creates new opportunities for some and risks for others. But in rapidly changing sea ice environments, maritime actors do still share some of the same goals in reducing uncertainties and increasing capacity to adapt to change. These are important synergies for planning and building mutually acceptable Arctic futures. Responsible innovation in sea ice SES can therefore only happen at an effective collaborative level: diverse stakeholders must make 
mutually agreeable plans for the future, including plans for observations, data gathering and provision of services through collaborative work. We explore this space of innovation by examining how a changing sea ice regime, environmental forecasting services, as well as socioeconomic and political developments in the Arctic might co-evolve. We use these insights to reflect on the future of responsible innovation in sea ice services.

\subsection{Responsible Innovation}

Addressing sustainable futures in the new geological epoch of the Anthropocene [37] is an endeavor in which researchers and practitioners are increasingly confronted with the dynamics between equity, i.e., the notion that everyone should have what they need for wellbeing in their given context, and sustainability [30]. Equity notably emerged, for example, as an essential building block of sustainability in the United Nations' Agenda 2030, and is foundational to its Sustainable Development Goals [38]. However, in conceptualizing the Anthropocene as a state change of the Earth system, we at once acknowledge it as a product of cumulative social, economic, and political interventions into planetary forces, while also recognizing the diffuse and unequal power relations of globalization $[39,40]$. In other words, while the totality of impacts from human development threaten the parameters of liveability for our species as a whole, the consequences of scientific and technological innovation (both positive and negative) have privileged societies unequally. These outcomes have impacted distributional equity (the allocation of resources, costs and benefits), recognitional equity (the acknowledgement of, and respect for, identities, values and rights), and procedural equity (the extent to which different groups are able to participate in governance) [30].

Innovation, like equity, is placed at the heart of sustainability in Agenda 2030, as a driver of economic productivity, industrialization, and technology development [38]. In this context, technological innovation is seen as a potential agent to facilitate more equitable futures. However, innovation is not just a process or a set of activities oriented to create solutions to problems, it is also an outcome, leading to changes, interventions and sometimes unforeseen impacts unfolding in society. The anticipating of these potential outcomes and the deliberate planning of development are therefore important dimensions of innovation driving equity in sustainability [26]. The regulations that govern technological innovation are products of social and political activities and socio-technical transitions, the shifts in which have also received increased attention as spaces of discourse through which power relations evolve [41,42]. This is because, much like innovation, the policy process itself (what kind of behaviors are encouraged, managed, or stopped by the government) involves problem definition and the framing of information in order to draw attention to certain issues, while minimizing the attention paid to others [43]. There are a myriad of socio-economic conditions afflicting society at any given point in time yet few rise to the level of importance that gets governing bodies involved [44]. Similarly, the location for points of intervention, where, and for whom socio-technical innovations are made or not made, has normative implications. These implications serve as a counterpoint to formerly reductionist, linear cause-effect governance of risks: Anticipating adverse events in the Anthropocene requires an understanding of emerging properties of social-ecological systems, tipping points, appropriate interventions and innovations, and conceptualizations of desired, or at least acceptable, futures $[26,30,45,46]$.

Macnaghten et al. found that responsible innovation itself is a paradox, in terms of the questions that are raised about levels of responsibility: "the paradox is that no one actor is in control, but everyone is implicated, has agency and therefore is responsible, interconnected in complex networks, at multiple scales, and in numerous ways" [47]. Because of this, ethical governance of innovation has to look beyond the traditional, product-related questions (e.g., how will risks and benefits be distributed), to also include process questions (who is in control? How should risks and benefits be defined and measured?), and purpose questions (who will benefit? what are alternatives?) [26]. To this end, Stilgoe et al. (2013) propose four mutually reinforcing dimensions of responsible innovation: anticipation, reflexivity, inclusion, and responsiveness, as a framework for responding to such questions [26]. The proposed 
dimensions prescribe the utility of foresight, multidisciplinary collaboration and user-centered design techniques, as well as the reflexive capacity of institutions and scientists in considering societal outcomes.

\section{Methods}

Relying on sea ice SES and responsible innovation literature as our conceptual lens, we bring together the diversity of interests and pressures that drive sea ice services now and until 2035, under a design hierarchy for the sea ice user-provider interface. We developed our schematic following two project phases, described below, based on initial scoping activities followed by a participatory scenario process (Figure 1). Our framework is complementary to the hierarchy proposed by Lee et al. for long-term Arctic observation networks [27], reconfigured to address the tenets of responsible innovation and four paradoxes of the sea ice services user-provider interface.

\section{SCOPING ACTIVITIES}

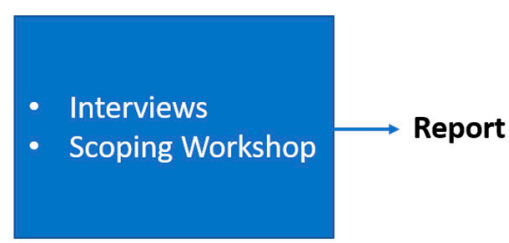

\section{SCENARIO WORKSHOP}

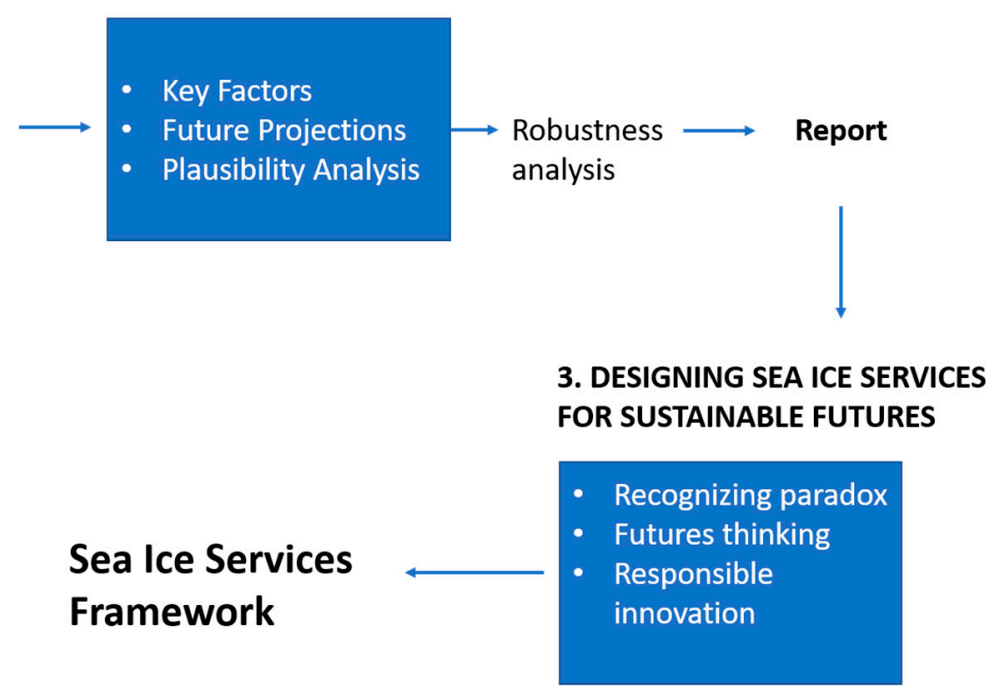

Figure 1. Diagram of research activities and outputs produced.

\subsection{Scoping Activities}

In phase 1 of the project, we linked scientific questions and stakeholder priorities that drive sea ice services development to reveal tensions due to paradoxical conditions. We began with a review of pertinent literature, followed by contact with stakeholders in the Arctic shipping sector for their thoughts about pressing questions as well as linked research needs for weather and sea ice forecast products. We had preliminary discussions with eight stakeholders and used their input to develop an agenda and representative participant list for a formal scoping workshop held in early 2018 in Tromsø, Norway. The workshop's activities engaged project partners and stakeholder advisory group members about important uncertainties in the planning and execution of activities, and ways in which sea ice services and forecast information can help decisions. Stakeholder advisory group members represented Greenlandic fishers and hunters, ice piloting services, expedition cruise operators, operational support (sea ice advise), search and rescue, and ice breaking services. In the course of the workshop activities, participants reflected on important information needs pertinent to planning and operations in their sectors. In these discussions participants reflected on planning routines, uncertainties that may arise due to weather and ocean conditions and services needed when considering alternate courses of action. Seven representatives from the Norwegian and Danish Meteorological Institutes attended the workshop to present their visions for potential areas for collaboration. The collective perspectives and experiences of distinct maritime sectors and metservice providers were summarized in a report following the workshop [3]. 


\subsection{Participatory Scenarios Process with Robustness Analysis}

To examine the broader social, political, and environmental processes that frame not only current demands, but also the need for future developments in climate and sea ice services provision, we organized a participatory scenarios workshop. Hosted at the Danish Meteorological Institute in Copenhagen in November 2018, recruited experts $(\mathrm{N}=23)$ represented the subsistence fishing and hunting, expedition cruise operations, ice pilotage, icebreaking services, intermediary operational support, maritime regulations and policy, Arctic search and rescue and maritime navigation sectors. With the exception of subsistence hunting and fishing and ice pilotage sectors, whose representatives had Greenlandic expertise, participants had multi-regional or Pan-Arctic expertise or operational experience. Seven participants were from Norway, eight from Denmark, four from Greenland, two from the U.K., and one from Finland and Canada each.

The workshop was facilitated by a participatory environment in which participant activities drove the agenda through task-specific breakout groups and synthesizing plenary discussions. The focal question: "What information is needed for optimal decisions toward safe and sustainable maritime activities now and through 2035?" served as the starting point for deliberations about both what is needed, and to what end. This focal question was chosen for two reasons. First, the SALIENSEAS project's mandate is to improve informational services for Arctic marine sectors. Second, all stakeholders, regardless of otherwise diverse operational backgrounds and expertise, share the goals of reducing uncertainties and increasing capacity to adapt to change. Through the focal question the workshop emphasized long-term safety and sustainability. Participants reflected about a variety of influential drivers of change, called Key Factors, that impact principal components of the focal question -safety, sustainability, information need- first considering definitions, and the role, of each component in reducing uncertainties; and then identifying drivers that impact these components. Finally, participants developed 2-5 future projections, or possible future states for each key factor describing the range of possible trends for each, outlined a brief narrative and assigned relative plausibility scores for each. The objective is to provide a weight towards those future projections that appear, to the scoring individual, more plausible to become the actual future of a given key factor.

Following the workshop, the data collected was used in a robustness analysis [48] to produce three scenario outcomes based on the selection of one future projection for each key factor. For this step, the core scenarios team scored the consistency of each pair of Future Projections in a pairwise consistency matrix. Consistency scores are designed to provide a metric to determine if two future projections from two different key factors are consistent to appear in the same scenario. As a last step, the combined scores were used by the core scenarios team to calculate the raw scenario bundles. Each of the three final scenarios had a unique emphasis on either consistency or plausibility, or a combination of both (robustness). For the purposes of this case study, only the most robust scenario outcomes will be considered and presented as these provide a middle of the road outcome balancing the most consistent and most plausible scenario bundles.

\section{Results and Discussion}

\subsection{Diversity of Needs \& Priorities}

There is a diversity of questions raised by scientists, policy makers and stakeholders in response to a rapidly changing sea ice regime $[3,27,49,50]$. The suite of science and policy questions confirm the socio-economic potential of sea ice services in their role as a decision support tool for diverse stakeholders. However, the focus of interest can be vastly different depending on the operational context of stakeholder groups. For those working on development planning policies, the focus is on whether and how increased access enables increased development, and the strategic and security dimensions of such changes. For those operating in Arctic waters the questions focus on how increasing access will impact activities and what information is needed to keep operations safe and sustainable. For Arctic communities, the questions are on the one hand about the social and ecological impacts from 
a changing ice regime on marine resources and local communities. On the other hand, communities too want to benefit from emergent economic opportunities and steer development toward desired futures. These diverging interests inform observation, monitoring and forecast needs, and also necessitate long-view targeted strategies and observational needs in the region.

The scoping workshop underlined the fact that the focus of scientific activities is driven not only by research needs, but the specific mandates of research institutes and domestic interests of a nation state. For example, the Norwegian and Danish meteorological institutes each have specific geographical regions under their jurisdiction for the provision of metocean monitoring and forecast products. For the SALIENSEAS project for example, this means that co-production activities, aimed at improving user-provider interaction, are likely to focus on different geographical contexts, communication challenges and user needs. This adds a layer of tension to the performance paradox, creating a gap between what is needed by users (international harmonization of data and services) and what is feasible for research institutes. For end-users, the parameters of salient, tailored products are highly sector-dependent. For example, a recurring theme in the Greenlandic context emphasized the importance of appropriately scaled products produced at high enough resolutions to be salient for local users, such as fishing vessel operators. However, for those actors who are involved with long-range planning of operations months and years in advance, lower-resolution projections are often sufficient. While some products need to have a short lead time in order to fit the decision processes of end-users, other forecasts are needed on extended time scales [3]. On the one hand, tailored and context specific collaborations between metservice partners and end-users is necessary through regular consultations to improve both the development and evaluation of forecast products and to strengthen the overall value chain of metocean communication for the European Arctic. On the other hand, this brings into prominence tensions stemming from the issues of inclusion and participation: whose questions and needs are met, and with what outcomes for SISS and ultimately, multi-scale equity in sustainable Arctic futures? Our survey of stakeholder questions, strategies and information needs revealed differences between groups of actors, but it also highlighted existing synergies and shared goals. The prevention and mitigation of environmental degradation was a common objective, as was the mutually beneficial relationship between maritime sectors and local communities, climate service providers and users.

These are some of the central issues that make up the problem definitions in the design of our sea ice services framework. In phase 2 of the framework development, we considered the interplay between paradoxes of the user-provider interface and likely future developments in the sea ice SES by 2035 . Here, we turn to the role of socio-economic scenarios in making explicit what tactics ice services need to adopt in order to work through these paradoxes toward responsible innovation, while supporting long-term stakeholder strategies and SISS monitoring needs.

\subsection{Future Scenarios}

\subsubsection{Key Factors}

The following is a summary of results compiled in a workshop report and technical documentation, which the reader is encouraged to consult for a detailed description of the scenario process and results [51].

The workshop produced 12 prioritized key factors (Table 1), or drivers of change, that impact information needs in safe and sustainable Arctic maritime activities now and through 2035. These factors include: (1) geopolitical stability, (2) accessibility of Arctic sea routes, (3) user-centric information infrastructures and data, (4) global economic trends, (5) demand for Arctic resources, (6) regulations and policy affecting Arctic operations, (7) major incidents and critical events, (8) predictability of sea ice variability, (9) fluctuating energy prices, (10) China's strategic plan, (11) sustainable and resilient local communities, and (12) the trajectory of technological development in marine technologies. These key factors emerged from an initial list of approximately 20, including some duplicates that were eliminated, and were prioritized in an activity where each participant voted on each key factor's 
importance and uncertainty. Table 1 shows the key factors and future projections with plausibility scores in parentheses.

Participants produced a total of 32 future projections across the 12 key factors, with the numbers ranging between $2-4$ future projections per key factor. For example, for geopolitical stability, the three future projections identified by participants range from total harmony and cooperation, to sporadic flexing of muscles via cyber-attacks but without military action, to Cold War Two over resources and regional dominance. Descriptions of key factors and future projections can be found in Supplementary Booklet S1.

Table 1. Key factors and future projections developed by workshop participants. Each future projection's relative plausibility score (in parentheses) and brief definitions listed. Full description can be found in Supplementary Booklet S1.

\begin{tabular}{|c|c|}
\hline Key Factors (and Their Future Projections) & $\begin{array}{l}\text { Key Factor Importance * } \\
\text { + Uncertainty Scores ** }\end{array}$ \\
\hline $\begin{array}{c}\text { Geopolitical stability } \\
\text { Cake for everyone (0.2): Increased collaboration; Common definitions of } \\
\text { sustainability }\end{array}$ & 44 \\
\hline $\begin{array}{c}\text { Accessibility of Arctic sea routes } \\
\text { Easy access (0.38): Reliable predictive models; Strengthened Search and Rescue } \\
\text { networks and infrastructure } \\
\text { Difficult access (0.48): Unreliable predictive models; More regulatory barriers } \\
\text { No access (0.14): More sea ice or sea ice variability; Ban on Arctic routes }\end{array}$ & 35 \\
\hline $\begin{array}{c}\text { User-centric information infrastructures and data } \\
\text { Global harmonization (0.2): Single-point data source; Increased co-design and } \\
\text { production with users } \\
\text { Few specialized, big actors (0.56): Public services remains the same; Increase in } \\
\text { commercial services } \\
\text { No development toward harmonization (0.24): Lack of centralized portals; } \\
\text { Fragmented infrastructure }\end{array}$ & 32 \\
\hline $\begin{array}{l}\text { Global economic trends } \\
\text { Arctic Rush (0.62): Rising incentives for resource development, destination } \\
\text { shipping, fishing, marine tourism } \\
\text { High-cost closing off (0.38): Regulatory pressures leading to increased rules; High } \\
\text { taxes, high field costs }\end{array}$ & 32 \\
\hline $\begin{array}{c}\text { Demand for Arctic resources } \\
\text { Seafood first (0.29): Global demand for eco-friendly protein grows; Seafood is \#1 } \\
\text { Arctic export commodity } \\
\text { Tourism first (0.49): Accessibility of Arctic destinations increases; Adventure } \\
\text { tourism grows } \\
\text { Fossil futures (0,22): Rising oil prices; Oil crisis creates higher demand for Arctic } \\
\text { fossil fuel }\end{array}$ & 32 \\
\hline $\begin{array}{c}\text { Regulations and policy affecting Arctic operations } \\
\text { Arctic } 5 \text { harmony (0.14): Harmonized, strict, enforced regulations and policies } \\
\text { Economic and commercial uses dominate (0.36): Environment takes a backseat to } \\
\text { economic efficiency } \\
\text { Environmentally driven regulation and policy (0.2): Environmental } \\
\text { considerations drive regulations } \\
\text { Fragmented, soft regulatory regime (0.3): Lack of uniformity in rules and } \\
\text { enforcement, rapid changes }\end{array}$ & 31 \\
\hline
\end{tabular}


Table 1. Cont.

\begin{tabular}{|c|c|}
\hline Key Factors (and Their Future Projections) & $\begin{array}{l}\text { Key Factor Importance * } \\
\text { + Uncertainty Scores ** }\end{array}$ \\
\hline $\begin{array}{c}\text { Major incidents and critical events } \\
\text { Ship crash (0.52): Incidents are on the rise; Inadequate Search and Rescue } \\
\text { capacities in region } \\
\text { Status quo (0,.48): Good record of marine operations; Traffic expands in linear } \\
\text { relation with local trade }\end{array}$ & 27 \\
\hline $\begin{array}{c}\text { Predictability of sea ice variability } \\
\text { Breakthrough (0.16): Breakthrough in sea ice prediction beyond weeks, } \\
\text { observational models } \\
\text { Gradual improvement of predictive models (0.64): Sea ice prediction improves } \\
\text { gradually over time } \\
\text { Unforeseen changes (0.2): Unforeseen changes in climatic trends make current } \\
\text { methods degrade }\end{array}$ & 24 \\
\hline $\begin{array}{l}\text { Fluctuating energy prices } \\
\text { Northern push (0.59): Profitable Arctic operations in extractive industries; } \\
\text { Increase in Arctic exports } \\
\text { Northern blockade (0,41): Decreased incentive for shipping industry to use } \\
\text { trans-Arctic routes }\end{array}$ & 23 \\
\hline $\begin{array}{c}\text { China's strategic plan } \\
\text { Mad Max (0.34): Shipping shares shift toward state-owned companies; Heavy } \\
\text { infrastructure investments } \\
\text { Chinese finger cuffs (0.66): China's strategic plans provoke preemptive } \\
\text { developments by Arctic nations }\end{array}$ & 23 \\
\hline $\begin{array}{c}\text { Sustainable and resilient local communities } \\
\text { Expat haven (0.44): Increased influx of people from outside the Arctic region } \\
\text { Education boost (0.26): Building community resilience via increased fate control } \\
\text { Tax haven (0.3): Fossil fuel industry making profit without being part of the local } \\
\text { communities }\end{array}$ & 20 \\
\hline $\begin{array}{c}\text { The trajectory of technological development in marine technologies } \\
\text { Techno-utopia for some, stormy seas for others (0.7): Favorable regulatory } \\
\text { frameworks and intense competition for smart marine technologies speed up } \\
\text { worldwide technical standardization and cooperation } \\
\text { Slow innovation and adoption (0.3): Rate of transition from emergent } \\
\text { technologies to mature technologies slows down }\end{array}$ & 20 \\
\hline \multicolumn{2}{|c|}{$\begin{array}{l}\text { *Importance prompt: "Which of the drivers most influence metocean and sea ice forecast needs in the region and } \\
\text { or which drivers have the most influence over future change?". ** Uncertainty prompt: "Which drivers represent } \\
\text { characteristics of systems that may be relevant to the focal question, but about which limited knowledge is available } \\
\text { and/or over which there is disagreement about their current or future state?". }\end{array}$} \\
\hline $\begin{array}{l}\text { The final set of key factors produced confirm the magnitude of influence } \\
\text { and geopolitical drivers on the informational needs of stakeholders. Loo } \\
\text { in Table 1, we observe that the highest-ranking techno-scientific key facto } \\
\text { infrastructures and data is in the third place, overtaken by geopolitical st } \\
\text { arctic sea routes. Much further down the list, we find predictability of sea ic } \\
\text { of technological developments in eighth and 12th place, respectively. The } \\
\text { factors stands testament to the primacy of Arctic regulations, pan-Arctic } \\
\text { trends and the influence of outside actors as necessary consideration for } \mathrm{r} \\
\text { for the enhancement and development of climate services. Most key fac } \\
\text { emphasizing the susceptibility of innovation and service developments to } \\
\text { control of participants. }\end{array}$ & $\begin{array}{l}\text { erted by socio-economic } \\
\text { ser-centric information } \\
\text { lity and accessibility of } \\
\text { ariability and trajectory } \\
\text { ttern of prioritized key } \\
\text { tions, global economic } \\
\text { onsible innovation and } \\
\text { s were globally driven, } \\
\text { tside forces beyond the }\end{array}$ \\
\hline
\end{tabular}




\subsubsection{Most Robust Scenario Bundle: All Aboard the Arctic Express}

The future projections bundled under the most robust scenario (Figure 2) together describe a future with continued interest from outside actors, increasing developments and investments in resource exploitation. All this is done rather pre-emptively where China's strategic investment plans are scrutinized and rejected, but then implemented within the bounds of existing Arctic regional capacities, in order to thwart outside geopolitical leverage. In this future the seafood industry is a clear winner as seafood becomes the main resource for Arctic exports. Geopolitical security continues with current trends of mostly peaceful pan-Arctic relations, with only occasional aggression demonstrated with cyber-attacks on infrastructure. Due to increased investments in sea ice observation, the gradual improvement of predictive models, and continued diminishing of sea ice, there will be easier access to Arctic sea routes. The improvement in information and data infrastructures and service provisions will not benefit all actors equally, with larger players enjoying an increase in the portfolio of specialized, subscription-based, user-friendly services but with public services remaining piecemeal as they struggle to finance growing service demands. Global economic trends will put pressure on all Arctic sectors, and the increase in both renewable and non-renewable resource development will result in increased marine traffic density in Arctic waters. Economic and commercial uses will dominate regulatory policies in Arctic operations, and environmental considerations will take a back seat. Major incidents and critical events follow a similar pattern as the status quo, with good record of marine operations and minor incidents only. Increasing energy prices will prompt increased exploration for fossil fuel sources, while prompting marine transport to invest in fuel-efficient, green ships. Growing Arctic economies will result in an influx of people from outside the Arctic region, creating sizable planning and decision-making challenges for small communities.

The type of outside investments that flow into sea ice information service improvements is an important decision-area to consider under this scenario. Would China's soft investments change the landscape of services offered, tipping the scales toward supporting commercial activities, and less on community data needs? What impacts would an unforeseen scenario have in which China's interest fades, or political conflict causes a sudden withholding of funds and services? Publicly funded services in such a scenario become especially relevant to keep the system resilient. And finally, the many ways in which sea ice information services can improve, such as centralized data portals, international harmonization of data provision, more affordable services, cannot happen without pan-Arctic collaboration, increased funding of public services, and regulatory changes.

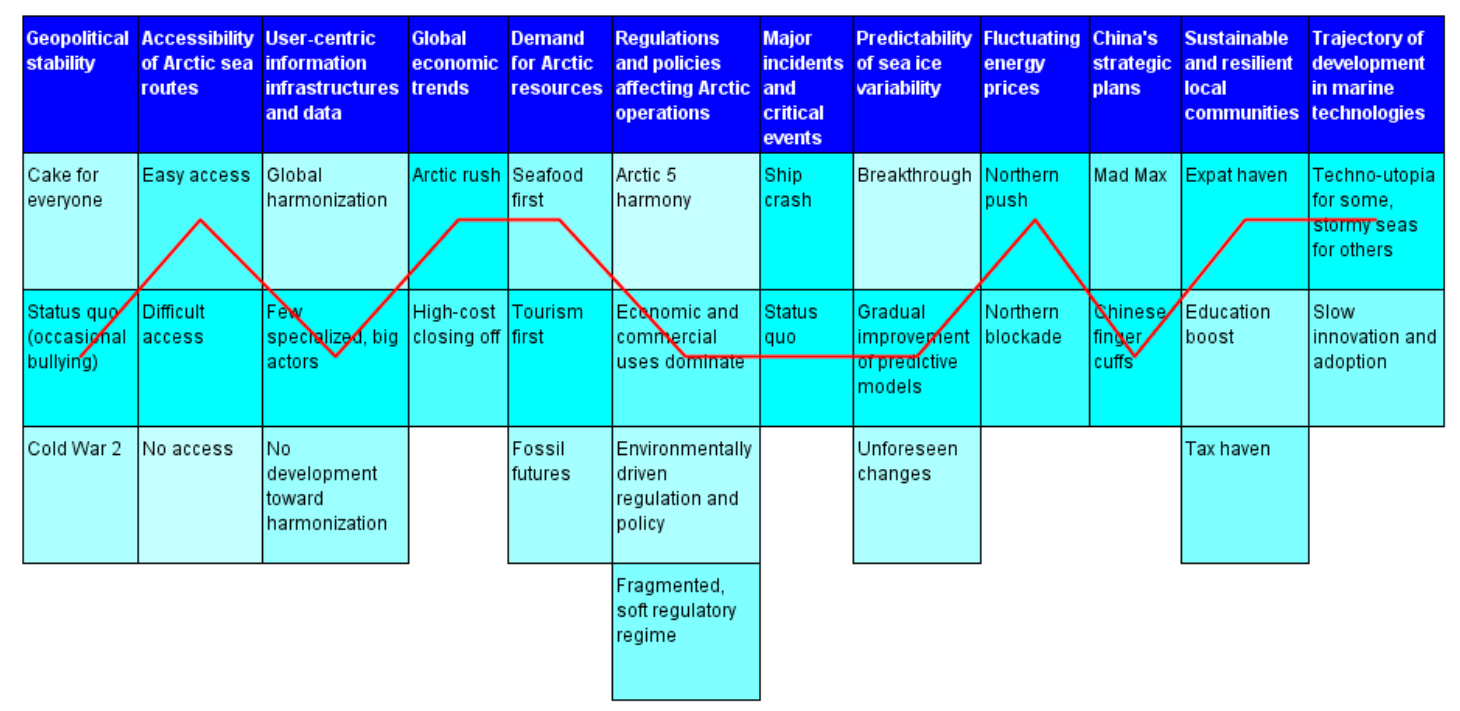

Figure 2. SALIENSEAS key factors (dark blue column headers), future projections (below each key factor heading), and most robust scenario bundle indicated by the red line. 
In this future the development of innovations and enhancements in service provisions do not benefit all actors, demand is not fully met, while the divide between the public and private portfolio of services grows. Global economic trends drive the growth of Arctic sectors, elevating the agendas of certain actors over others, and impacting the type of service developments that occur. Arctic communities have to confront major transitions in local demographics and sectoral shifts, pushing the limits of community adaptive capacity. These shifts increase the need for climate and sea ice service provision oriented to local-scale priorities, while gaps in such services increase risks to subsistence activities and emerging entrepreneurial opportunities. The cumulative impacts from these developments on marine environments will largely depend on the extent to which regulations incentivize green developments and partnerships with local communities, and disincentivize pollution. This scenario also highlights the paradox underlying the growing influence of non-Arctic actors in Arctic affairs, as their involvement can, on the one hand, bring added expertise and capacities, but also pressure Arctic stakeholders and institutions to adopt different modes of research, value-sets, and governance tied to non-Arctic interests [14].

\subsection{A Sea Ice Services Framework toward Responsible Innovation}

We now turn to the synthesis of our findings about sea ice social-ecological systems, SISS, and relevant information needs in a design schematic of sea ice services. Central to our framework are the tenets of responsible innovation and a coproduced sea ice services hierarchy that address user needs while working through paradoxical conditions.

Figure 3 presents this design schematic for an enhanced user-producer interface. Three components: scientific research questions, SISS, and stakeholder-desired outcomes anchor a framework in which problem definitions and long-view strategies must be parsed out to inform the planning of sea ice services. An ice-diminished Arctic Ocean drives problem definitions and research questions about the informational needs of researchers. The SISS perspective makes explicit ways in which diminishing sea ice creates risks and opportunities due to shifting sea ice service capacities. For example, land-fast ice stability supports users for whom the ice edge serves as a platform for activities. Trends in open-water timing informs users for whom ice serves as a regulator of transportation corridors. The same is true on a shorter time scale for ice hazard alerts. Ice-associated primary production influences biodiversity and the health of important marine species; for instance, tracking the available energy from lower trophic levels to inform stakeholders on the health of subsistence species. These perspectives inform long-term observing and monitoring needs. Stakeholder-desired outcomes add a normative dimension to managing risks for positive outcomes and increased equity in sustainability. Responsible innovation as the institutional space that governs development in sea ice SES, runs in parallel with the creation of long-term strategies. These strategies provide a space for the prioritization of policies and approaches to resolve outlined issues and problems, focusing on ways in which sea ice observation, monitoring, and services can aid this process.

Four paradoxes emerge as seemingly irresolvable tensions in the sea ice services user-provider interface. As detailed in Section 1.2, experts face the paradoxes of performing. These are dilemmas that are embedded in the dual requirement of simultaneously expertise- and user-driven innovation. The paradox of SISS demands that sea ice services are oriented toward diverse, often conflicting values and functions accrued to sea ice users. The paradox of desired futures pressures experts to understand and balance trade-offs that arise when the consequences of the same solution benefit some, while disadvantaging others. Finally, the paradox of responsible innovation, that no one actor is in complete control but all are impacted, exposes areas of institutional and regulatory vacuum. In response to the above demands and tensions, sea ice services must adopt tactical actions that can support the diversity of long-term strategies. 


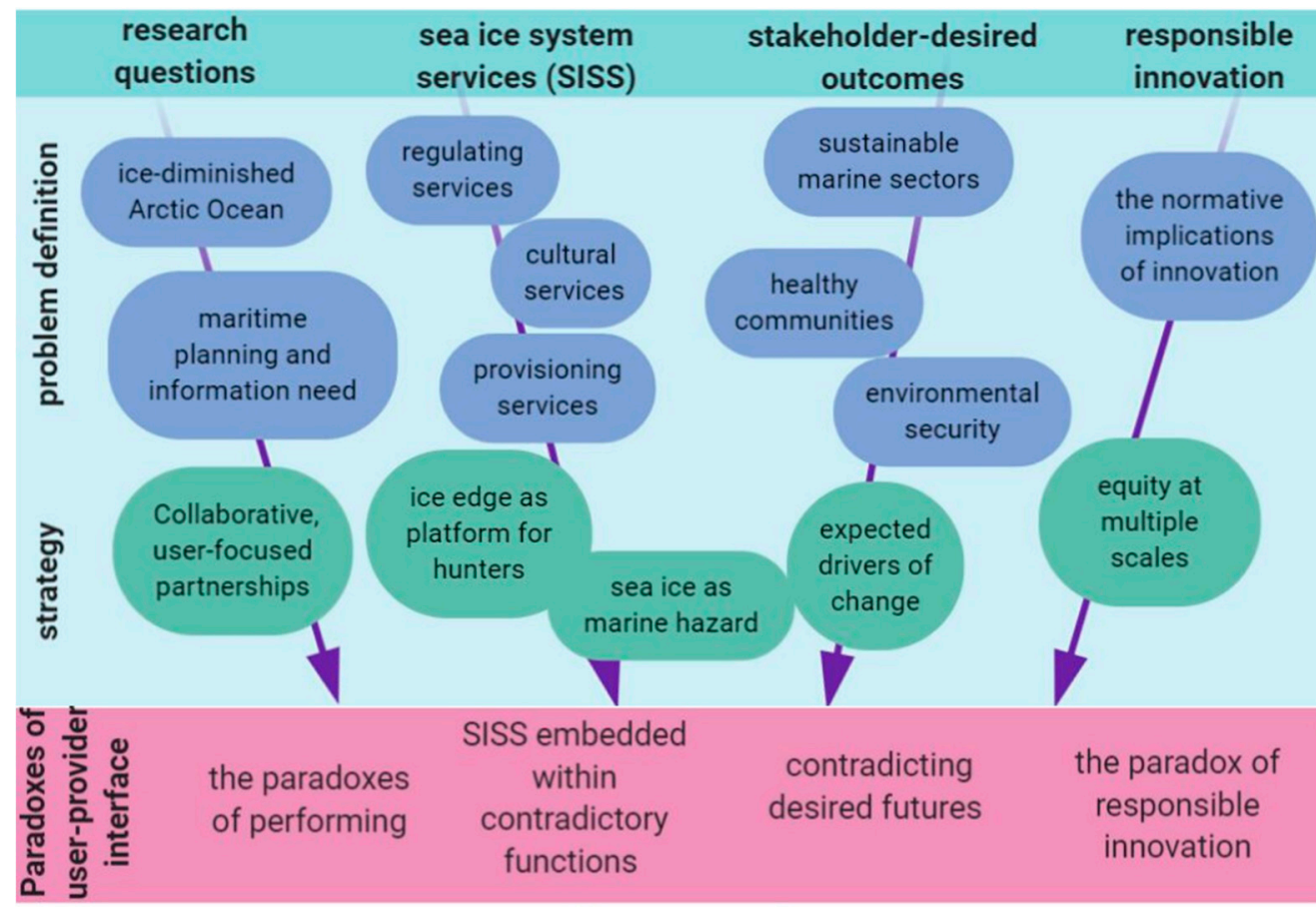

\section{Sea ice services}

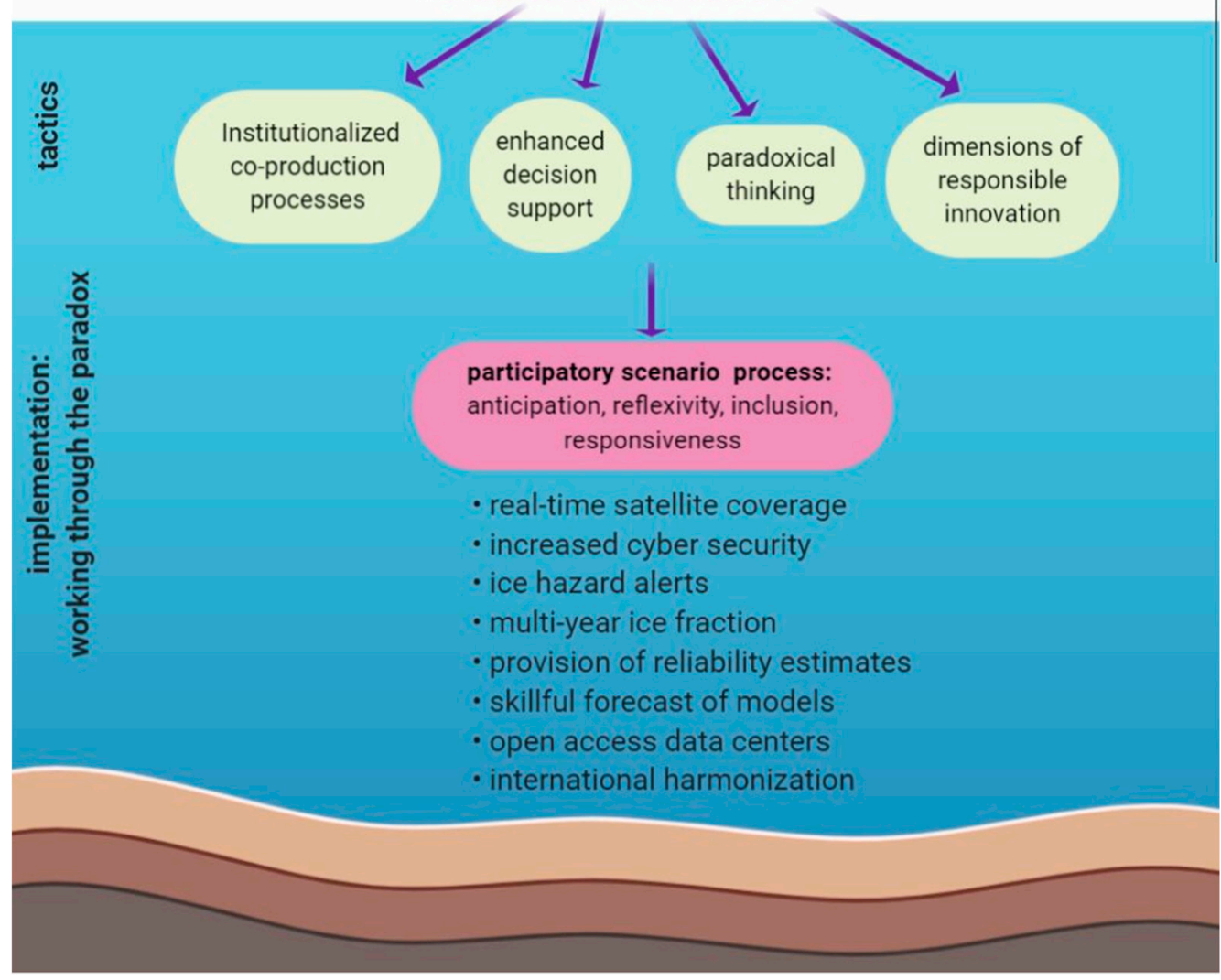

Figure 3. Schematic of hierarchy for enhanced sea ice services user-producer interface from problem definition to strategy, tactics, and operationalization. The coloured ovals show example topics or issues relevant at each level of the hierarchy. The bulleted list at the bottom is a sample set of suggestions for enhancements or continued emphasis in sea ice services until 2035, resulting from the SALIENSEAS scenario process. 
The tactics which sea ice service providers may adopt in response to user needs and paradoxical pressures can be organized along a few main themes. The first tactic is the institutionalizing of the regular exchange of ideas between providers and users of services, by making coproduction a formal component of product development in perpetuity. As coproduction becomes a structured component of product development and evaluation, it enhances not only the user-friendliness of information but also makes possible long-term partnerships and mutual anticipation of needed changes. Second, the continued prioritization of products and services maximized to the benefit of diverse user groups will continue to play a crucial role in meeting functional requirements of enhanced decision support. Third, sea ice service providers will continue to confront contradictory demands for services and solutions, having to increasingly adopt working through [16] routines and methods in paradoxical thinking (see Section 1.2). Lastly, the four dimensions of responsible innovation (inclusion, reflexivity, anticipation, and responsiveness) [26,46], when integrated into organizational culture and practices, aid the previous three tactics while strengthening the stewardship of sustainable outcomes for diverse stakeholders.

At the bottom of the design hierarchy is the coproduction implementation space, where socio-economic scenarios aid the realization of the four tactics discussed. The scenario results inform areas for innovation and service enhancements that are mutually beneficial for all stakeholders toward sustainable futures. Here, we briefly reflect on the potential of participatory scenarios to support the user-provider interface, with lessons learned especially configured to supporting the tactic of responsible innovation.

Anticipation: Participatory scenario processes produce a prioritized set of agreed-upon key factors that are likely to shape stakeholders' informational needs into the future as they adapt to changes. These drivers encompass diverse perspectives about expected developments and uncertainties, as well they inform service providers about what indicators to track to keep abreast of changes. As participants assign plausibilities to the various trajectories, or likely future state of each key factor, they inform priorities for the planning of research activities, or signal when diplomatic activities are desirable to affect policy change. For example, the future projection 'Status Quo: occasional bullying' for key factor 'Geopolitical Stability' foresees a still largely peaceful Arctic region in 2035, but the equilibrium is punctuated by displays of non-military aggression. As a result, the international coordination of data centers and cyber security, and the security of information infrastructures will play an especially important role in the resilience of Arctic communities and industries. Furthermore, although stakeholder participation can exacerbate tensions from the paradoxes of performing [16], the scenario process also makes explicit the types of developments that will be likely needed to produce high-impact research in the coming years.

Reflexivity: Through deliberations of a focal question and shared goals among stakeholders, participants confront their own as well as each other's aims, ideas, underlying assumptions, uncertainties and limitations. Additionally, connections between research practices and governance, as well as institutional capacities are deliberated among participants. These lines of reflexive inquiry can serve as a vehicle for getting participants to think outside a single worldview, broaden their scope of analysis and find common grounds for shared futures. These are traits that facilitate a working through the paradox paradigm. Additionally, scenarios reveal important power dynamics among the participants and the stakeholder groups they represent. For example, the key factor 'Regulations and policies affecting Arctic operation' was represented in the 2035 robust bundle by the future projection 'Economic and commercial uses dominate'. This projection describes a future in which industry essentially writes the codes and standards that manage risks and oversee operations, and where environmental considerations take a backseat to economic efficiency. Related to this development, the key factor 'sustainable and resilient local communities' is projected to trend toward 'Expat Haven', with communities grappling with major demographic changes due to the influx of people. This dynamic has in impact on the demands placed on, and investments made in local infrastructure and services. One way in which sea ice services could support communities adapting to changes, 
for example, is through intensifying the dialogue between the research and operational forecaster communities. Operational forecasters, the staff who produce forecast products, can help to establish strategic collaborations with specific user groups, such as communities grappling with pressures on their economic and cultural capital, and help to target development strategies that best provide decision support [52].

Inclusion: Inclusive, participatory knowledge production paradigms are foundational to responsible innovation [26]. The long-term sustainability of Arctic communities and sectors are tied to inclusive, collaborative learning about the dynamics of sea ice SES, and the trajectory of innovations that shape their futures. It is important then to engage with a diverse array of stakeholder expertise, and to consider broad decision spaces beyond any single product or service. Participatory scenario processes meet these criteria. In the context of sea ice services coproduction, the makeup of workshop participants determines the extent to which the deliberations and the workshop results have the potential to alleviate paradoxical tensions in the user-provider interface. As a result, the scenario output speaks to a wide range of socio-economic drivers of change from the perspective of diverse stakeholders.

Responsiveness: Responsiveness in responsible innovation speaks to the capacity to change course in response to new knowledge, perspectives, as well as changing public values and circumstances [26]. In this sense, innovation has to consider and respond to the requirements of both the product (in this case sea ice services) and the process itself, such as monitoring the success of anticipation, reflexivity, and inclusion. In our case, we intended to be responsive to stakeholders through iterative designs in our collaborations, integrating new knowledge and perspectives into subsequent processes. The scenario process supported this objective. Through the use of socio-economic scenarios, we increased the anticipatory relevance of project outputs, by considering the temporal longevity of deliverables. In other words, designing resilient products that can stand the tests of time in rapidly changing decision environments is one way that service providers can demonstrate responsiveness. In another example, we used the socio-economic scenarios as a backdrop to develop the serious game Icewise. The game incorporates a new seasonal sea ice forecast product, developed by project partners, into a gaming environment. In its final phase, our project will engage potential users of this new forecast in simulation-gaming exercises. In doing so, we aim to test, and ultimately co-model with participants, the usefulness of newly developed [53] reliability estimates for seasonal sea ice forecasts. Through this game, the developers of this service gain insights about ways in which their product can be further enhanced to meet expected challenges until 2035.

\section{Conclusions}

Our suggested framework expands on the previous literature that focused on the hierarchy of activities involved in the design and implementation of long-term observation networks. This paper carried this research further, focusing on the principles of responsible innovation and conditions of paradox in sea ice SES. In our research, we applied socio-economic scenario outcomes around an otherwise basic science and technology-dominated field in a complementary role to support collaboration about the long-term informational needs of diverse groups of actors. The scenarios revealed some of the broader, global processes that shape sea ice SES dynamics and the supporting role of international, national and local policy and frameworks in producing salient sea ice services. The scenarios process demonstrated ways in which diverse stakeholders can come together to anticipate upcoming information needs, reflect under a set of acceptable common objectives-in this case safety and sustainability—and articulate relevant spaces for innovation.

Although the sea ice user-provider interface is rife with paradoxical tensions, our suggested framework works through these challenges by the adoption of tactics that work in tandem with multi-stakeholder, multi-context strategies for sustainable futures. The framework, at its core, has a moderating effect on innovation's role in shifting power relations by easing tensions from the paradoxes of the user-provider interface. It does so through the broadening of perspectives about products 
and processes of innovation, what is and will be needed, and what is and will be feasible to provide to support the resilience and adaptive capacity of diverse groups of users. This moves the space of innovation beyond the logic of exclusion (either/or, winners versus losers) toward a spectrum of definitions and shared meanings around sustainable futures. This process, in turn, fosters the planning for accountability and responsible innovation in the deliberate making of choices about the effects from scientific and technological innovation.

The challenges currently confronting sea ice service providers will be faced more broadly by Arctic institutions, regulators and communities everywhere as rapid changes continue. Tensions from paradoxical conditions will continue to impact how issues on the policy agenda are perceived and what treatment options are formulated in response. As decision makers and stakeholders are increasingly confronted by difficult either/or choices, a broadening of the scope of analysis of the problems is needed [14]. In this research we offered participatory socio-economic scenarios as a platform for broad-scoped problem analysis, through which diverse narratives can converge into shared truths about the future. Such platforms can help to ease Arctic paradoxes by producing knowledge that transcends any one sector, affiliation, or discipline, but one that is still relational and contextual, and therefore complementary to global frameworks. Our participants offered practical solutions relevant for monitoring sustainability in sea ice social-ecological systems, and for the provision of information to aid adaptive action. These include, for example, real-time satellite coverage, increased cyber security, ice hazard alerts, multi-year ice fraction, provision of reliability estimates with forecasts, skillful forecast of models, open access data centers, and international harmonization of data and services. This list makes clear that the enhancements required demand not only technical and infrastructural investments, but international cooperation and policy change as well. As science strives to be increasingly policy-relevant, policies too must be adaptive and institutions able to reinvent themselves in order to remain salient.

Supplementary Materials: The following are available online at http://www.mdpi.com/2071-1050/12/2/448/s1. A single supplementary material (S1) is published online alongside the manuscript titled "Key Factors".

Author Contributions: Conceptualization, B.B., O.A.L. and M.L.; Data curation, B.B. and M.L.; Formal analysis, B.B.; Funding acquisition, M.L.; Methodology, B.B.; Visualization, B.B. and O.A.L.; Writing-original draft, B.B.; Writing-review \& editing, B.B., O.A.L. and M.L. All authors have read and agreed to the published version of the manuscript.

Funding: The SALIENSEAS project, part of the ERA4CS programme, is co-funded by the Netherlands Organisation for Scientific Research and by the Horizon 2020 Framework Programme of the European Union (Grant 690462). This is a contribution to the Year of Polar Prediction (YOPP), a flagship activity of the Polar Prediction Project (PPP), initiated by the World Weather Research Programme (WWRP) of the World Meteorological Organisation (WMO).

Acknowledgments: We thank the participants who generously gave their time and expertise in our workshops. We also wish to thank the three anonymous reviewers whose suggestions have helped to improve the manuscript.

Conflicts of Interest: The authors declare no conflict of interest.

\section{References}

1. Meredith, M.; Sommerkorn, M.; Cassotta, S.; Derksen, C.; Ekaykin, A.; Hollowed, A.; Kofinas, G.; Mackintosh, A.; Melbourne-Thomas, J.; Muelbert, M.M.C.; et al. Polar Regions. In IPCC Special Report on the Ocean and Cryosphere in a Changing Climate; Pörtner, H.O., Roberts, D.C., Masson-Delmotte, V., Zhai, P., Tignor, M., Poloczanska, E., Mintenbeck, K., Nicolai, M., Okem, A., Petzold, J., et al., Eds.; Intergovernmnental Panel on Climate Change: Geneva, Switzerland, 2019; pp. 1-178.

2. Wang, M.; Overland, J.E. A sea ice free summer Arctic within 30 years: An update from CMIP5 models. Geophys. Res. Lett. 2012, 39. [CrossRef] 
3. Lamers, M.; Knol, M.; Müller, M.; Blair, B.; Jeuring, J.; Rasmussen, T.; Sivle, A. Enhancing the Saliency of Climate Services for Marine Mobility Sectors in European Arctic Seas (SALIENSEAS): Stakeholder Advisory Group Workshop Report. 2018. Available online: http:/salienseas.com/wpcontent/uploads/2018/ 04/SALIENSEAS_Report_SAG_coscoping.pdf (accessed on 2 January 2020).

4. Eicken, H.; Lovecraft, A.L.; Druckenmiller, M.L. Sea-ice system services: A framework to help identify and meet information needs relevant for Arctic observing networks. Arctic 2009, 62, 119-136. [CrossRef]

5. Lemos, M.C.; Kirchhoff, C.J.; Ramprasad, V. Narrowing the climate information usability gap. Nat. Clim. Chang. 2012, 2, 789-794. [CrossRef]

6. Meadow, A.M.; Ferguson, D.B.; Guido, Z.; Horangic, A.; Owen, G.; Wall, T. Moving toward the Deliberate Coproduction of Climate Science Knowledge. Weather Clim. Soc. 2015, 7, 179-191. [CrossRef]

7. Porter, J.J.; Dessai, S. Mini-me: Why do climate scientists' misunderstand users and their needs? Environ. Sci. Policy 2017, 77, 9-14. [CrossRef]

8. Dawson, J.; Hoke, W.; Lamers, M.; Liggett, D.; Ljubicic, G.; Mills, B.; Stewart, E.; Thoman, R. Navigating Weather, Water, Ice and Climate Information for Safe Polar Mobilities; World Meteorological Organization: Geneva, Switzerland, 2017.

9. Parker, W.S.; Lusk, G. Incorporating user values into climate services. Bull. Am. Meteorol. Soc. 2019, 100, 1643-1650. [CrossRef]

10. Bremer, S.; Wardekker, A.; Dessai, S.; Sobolowski, S.; Slaattelid, R.; van der Sluijs, J. Toward a multi-faceted conception of co-production of climate services. Clim. Serv. 2019, 13, 42-50. [CrossRef]

11. Lövbrand, E. Co-producing European climate science and policy: a cautionary note on the making of useful knowledge. Sci. Public Policy 2011, 38, 225-236. [CrossRef]

12. Hamaker, R.; Jimenez-Alonso, E.; Rycerz, A.; Baglee, A.; Stegmaier, P. Analysis of Existing Data Infrastructure for Climate Services. 2018, p. 71. Available online: http://eu-macs.eu/wp-content/uploads/2016/12/EUMACSD1.3_revision.pdf (accessed on 2 January 2020).

13. Jørgensen, P.S.; Folke, C.; Carroll, S.P. Evolution in the Anthropocene: Informing Governance and Policy. Annu. Rev. Ecol. Evol. Syst. 2019, 50, 527-549. [CrossRef]

14. Lovecraft, A.L.; Cost, D. Policy Paradoxes: Challenges Confronting the Contemporary Arctic. In Leadership for the North: The Influence and Impact of Arctic Council Chairs; Nord, D.C., Ed.; Springer International Publishing: Cham, Germany, 2019; pp. 13-32.

15. Buixadé Farré, A.; Stephenson, S.R.; Chen, L.; Czub, M.; Dai, Y.; Demchev, D.; Efimov, Y.; Graczyk, P.; Grythe, H.; Keil, K.; et al. Commercial Arctic shipping through the Northeast Passage: routes, resources, governance, technology, and infrastructure. Polar Geogr. 2014, 37, 298-324. [CrossRef]

16. Lüscher, L.S.; Lewis, M.W. Organizational change and managerial sensemaking: Working through paradox. Acad. Manag. J. 2008, 51, 221-240. [CrossRef]

17. Cunha, M.; Clegg, S. Persistence in paradox. Perspect. Process. Organ. Stud. Dualities Dialectics Paradoxes Organ. Life 2018, 8, 14-34.

18. Mol, A.P. Environmental Reform in the Information Age. The Contours of Informational Governance; Cambridge University Press: Cambridge, UK, 2008.

19. Gupta, A. Transparency in Global Environmental Governance: A Coming of Age? MIT Press: Cambridge, MA, USA, 2010.

20. Lamers, M.; Pristupa, A.; Amelung, B.; Knol, M. The changing role of environmental information in Arctic marine governance. Curr. Opin. Environ. Sustain. 2016, 18, 49-55. [CrossRef]

21. Miller, R. Learning, the future, and complexity. An essay on the emergence of futures literacy. Eur. J. Educ. 2015, 50, 513-523. [CrossRef]

22. Bohensky, E.; Butler, J.R.; Costanza, R.; Bohnet, I.; Delisle, A.; Fabricius, K.; Gooch, M.; Kubiszewski, I.; Lukacs, G.; Pert, P. Future makers or future takers? A scenario analysis of climate change and the Great Barrier Reef. Global Environ. Chang. 2011, 21, 876-893. [CrossRef]

23. Wollenberg, E.; Edmunds, D.; Buck, L. Using scenarios to make decisions about the future: anticipatory learning for the adaptive co-management of community forests. Landsc. Urban Plan. 2000, 47, 65-77. [CrossRef]

24. Oteros-Rozas, E.; Ravera, F.; Palomo, I. Participatory scenario planning in place-based social-ecological research: insights and experiences from 23 case studies. Ecol. Soc. 2015, 20, 32. [CrossRef] 
25. Sheppard, S.R.; Shaw, A.; Flanders, D.; Burch, S.; Wiek, A.; Carmichael, J.; Robinson, J.; Cohen, S. Future visioning of local climate change: A framework for community engagement and planning with scenarios and visualisation. Futures 2011, 43, 400-412. [CrossRef]

26. Stilgoe, J.; Owen, R.; Macnaghten, P. Developing a framework for responsible innovation. Res. Policy 2013, 42, 1568-1580. [CrossRef]

27. Lee, O.; Eicken, H.; Kling, G.; Lee, C. A Framework for Prioritization, Design and Coordination of Arctic Long-term Observing Networks: A Perspective from the U.S. SEARCH Program. Arctic 2015, 68. [CrossRef]

28. Palosaari, T.; Tynkkynen, N. Arctic securitization and climate change. Handb. Politics Arctic 2015, 87-104. [CrossRef]

29. Berkes, F.; Folke, C.; Colding, J. Linking Social and Ecological Systems: Management Practices and Social Mechanisms for Building Resilience; Cambridge University Press: Cambridge, UK, 1998.

30. Leach, M.; Reyers, B.; Bai, X.; Brondizio, E.S.; Cook, C.; Díaz, S.; Espindola, G.; Scobie, M.; Stafford-Smith, M.; Subramanian, S.M. Equity and sustainability in the Anthropocene: A social-ecological systems perspective on their intertwined futures. Glob. Sustain. 2018, 1. [CrossRef]

31. Gunderson, L.H.; Holling, C.S. Panarchy: Understanding Transformations in Human and Natural Systems; Island Press: Wahington, DC, USA, 2002.

32. Young, O.R. Sugaring off: enduring insights from long-term research on environmental governance. Int. Environ. Agreem. Politics Law Econ. 2013, 13, 87-105. [CrossRef]

33. Berkes, F.; Turner, N.J. Knowledge, Learning and the Evolution of Conservation Practice for Social-Ecological System Resilience. Hum. Ecol. 2006, 34, 479-494. [CrossRef]

34. McGinnis, M.D.; Ostrom, E. Social-ecological system framework: initial changes and continuing challenges. Ecol. Soc. 2014, 19. [CrossRef]

35. Blair, B.; Lovecraft, A.; Hum, R. The Disaster Chronotope: Spatial and Temporal Learning in Governance of Extreme Events. In Governance of Risk, Hazards and Disasters: Trends in Theory and Practice; Forino, G., Bonati, S., Calandra, L.M., Eds.; Routledge: Abingdon, UK, 2018; pp. 43-64.

36. Lovecraft, A.L.; Meek, C.; Eicken, H. Connecting scientific observations to stakeholder needs in sea ice social-environmental systems: the institutional geography of northern Alaska. Polar Geogr. 2013, 36, 105-125. [CrossRef]

37. Crutzen, P.J. The "anthropocene". In Earth system Science in the Anthropocene; Springer: Berlin/Heidelberg, Germany, 2006; pp. 13-18.

38. United Nations. Transforming Our World: The 2030 Agenda for Sustainable Development. General Assembley 70 Session. 2015. Available online: https://sustainabledevelopment.un.org/post2015/transformingourworld/ publication (accessed on 2 January 2020).

39. Johnson, H. The Anthropocene as a Negative Universal History. Adorno Stud. 2019, 3, 47-63.

40. Chakrabarty, D. The climate of history: Four theses. Crit. Inq. 2009, 35, 197-222. [CrossRef]

41. Moulaert, F. The international Handbook on Social Innovation: Collective Action, Social Learning and Transdisciplinary Research; Edward Elgar Publishing: Trotterham, UK, 2013.

42. Voß, J.-P.; Smith, A.; Grin, J. Designing long-term policy: rethinking transition management. Policy Sci. 2009, 42, 275-302. [CrossRef]

43. Schon, D.A.; Rein, M. Frame reflection: Toward the Resolution of Intractrable Policy Controversies; Basic Books: New York, NY, USA, 1995.

44. Dan Wood, B.; Doan, A. The politics of problem definition: Applying and testing threshold models. Am. J. Political Sci. 2003, 47, 640-653. [CrossRef]

45. Brondizio, E.S.; O’brien, K.; Bai, X.; Biermann, F.; Steffen, W.; Berkhout, F.; Cudennec, C.; Lemos, M.C.; Wolfe, A.; Palma-Oliveira, J. Re-conceptualizing the Anthropocene: A call for collaboration. Glob. Environ. Chang. 2016, 39, 318-327. [CrossRef]

46. Owen, R.; Stilgoe, J.; Macnaghten, P.; Gorman, M.; Fisher, E.; Guston, D. A framework for responsible innovation. Responsible Innov. Manag. Responsible Emerg. Sci. Innov. Soc. 2013, 31, 27-50.

47. Macnaghten, P.; Owen, R.; Stilgoe, J.; Wynne, B.; Azevedo, A.; de Campos, A.; Chilvers, J.; Dagnino, R.; Di Giulio, G.; Frow, E. Responsible innovation across borders: Tensions, paradoxes and possibilities. J. Responsible Innov. 2014, 1, 191-199. [CrossRef]

48. Gausemeier, J.; Fink, A.; Schlake, O. Scenario management: An approach to develop future potentials. Technol. Forecast. Soc. Chang. 1998, 59, 111-130. [CrossRef] 
49. Crépin, A.-S.; Karcher, M.; Gascard, J.-C. Arctic climate change, economy and society (ACCESS): Integrated perspectives. Ambio 2017, 46, 341-354. [CrossRef] [PubMed]

50. Dobricic, S.; Monforti Ferrario, F.; Pozzoli, L.; Wilson, J.; Gambardella, A.; Tilche, A. Impact Assessment Study on Societal Benefits of Arctic Observing Systems. 2018. Available online: https://publications.jrc.ec. europa.eu/repository/bitstream/JRC113327/kjna29400enn.pdf (accessed on 2 January 2020).

51. Blair, B.; Muller-Stoffels, M. Maritime Futures 2035: The Arctic Region: Workshop Report E Technical Documentation; Wageningen University and Research: Wageningen, The Netherlands, 2019; p. 92. Available online: http://salienseas.com/wp-content/uploads/2019/06/Workshop_Report.pdf (accessed on 2 January 2020).

52. Jeuring, J.; Knol-Kauffman, M.; Sivle, A. Toward valuable weather and sea-ice services for the marine Arctic: Exploring user-producer interfaces of the Norwegian Meteorological Institute. Polar Geogr. 2019, 1-21. [CrossRef]

53. Palerme, C.; Müller, M.; Melsom, A. An intercomparison of verification scores for evaluating the sea ice edge position in seasonal forecasts. Geophys. Res. Lett. 2019, 46, 4757-4763. [CrossRef]

(C) 2020 by the authors. Licensee MDPI, Basel, Switzerland. This article is an open access article distributed under the terms and conditions of the Creative Commons Attribution (CC BY) license (http://creativecommons.org/licenses/by/4.0/). 